\title{
Single institutional experience of peripheral applications of a liquid embolic agent: Ethylene Vinyl Alcohol Copolymer
}

\author{
Abhijit L. Salaskar , Faezeh Razjouyan, Alexander L. Cho, Rishi R. Sood, Andrew Akman, Daniel Scher, \\ Anthony C. Venbrux and Shawn N. Sarin
}

\begin{abstract}
Objective: To evaluate the safety and efficacy of ethylene vinyl alcohol (EVOH) copolymer for the treatment of a variety of peripheral vascular pathologies.

Results: Between October 2010 and October 2017, 43 patients who underwent total 54 EVOH embolization procedures for the treatment of peripheral vascular pathologies were included. The cases which involved the use of $\mathrm{EVOH}$ for the treatment of nonvascular, neurologic, ophthalmologic, otolaryngologic or head-neck pathologies were excluded. The demographic data, technical and clinical success rates, and procedure-related details and complications were obtained. The most common indications for $\mathrm{EVOH}$ embolization were type II endoleaks $(n=18)$ and peripheral arteriovenous malformations $(n=14)$. The majority of cases $(62.5 \%)$ used EVOH without any adjunct embolic material. The results of this study showed $100 \%$ technical success rates and $89 \%$ clinical success rates. No events of nontarget embolization or other procedure-related complications were noted. The mortality \& morbidity rates were $0 \%$. The loss to follow up rate was 16\% (9/54). The mean follow-up period was 134 days (range, 30 to 522 days).
\end{abstract}

Conclusion: The single institutional experience supports the safety and efficacy of $\mathrm{EVOH}$ embolization in the treatment of various peripheral vascular conditions.

Keywords: Ethylene vinyl alcohol copolymer, EVOH, Onyx embolization, Arteriovenous malformations, Endoleak type II, Pseudoaneurysm

\section{Background}

Ethylene Vinyl Alcohol Copolymer, EVOH (Onyx ${ }^{\mathrm{Tm}}$, Medtronic, Minneapolis, MN) is a non-adhesive, nonabsorbable, permanent liquid embolic agent. The use of $\mathrm{EVOH}$ for preoperative embolization of cerebral arteriovenous malformations (AVMs) has been FDA approved since 2005 (Loh \& Duckwiler, 2010), and has since expanded to treat AVMs and aneurysms in the head, neck, and spine. However, the use of EVOH for the treatment of peripheral pathologies remains limited. In the periphery, it has been used in the treatment of type II endoleaks

\footnotetext{
* Correspondence: abhijitlausalaskar@ymail.com

Division of Vascular and Interventional Radiology, George Washington University Hospital, Washington, DC 20037, USA
}

(EL-2) (Massis et al., 2012) and peripheral AVMs (Cantasdemir et al., 2012; Numan et al., 2004). Other rare off-label uses of $\mathrm{EVOH}$ include embolization of gastrointestinal hemorrhage (Urbano et al., 2014), post-traumatic hemorrhage (Müller-Wille et al., 2011), type I endoleaks (Eberhardt et al., 2014), pulmonary hemorrhages (Bommart et al., 2011; Izaaryene et al., 2016), pseudoaneurysms (PSAs) (Vanninen \& Manninen, 2007), pelvic AVMs (Castaneda et al., 2002; Wohlgemuth et al., 2015), and neoplasms. (Regine et al., 2015) The existing literature is in the form of case reports or series. The possible reasons for the slow adoptation of this agent in the treatment of peripheral pathologies could be secondary to its perceived technical complexity, inadequate training, feared complications, high

\section{Springer Open}

() The Author(s). 2020 Open Access This article is licensed under a Creative Commons Attribution 4.0 International License, which permits use, sharing, adaptation, distribution and reproduction in any medium or format, as long as you give appropriate credit to the original author(s) and the source, provide a link to the Creative Commons licence, and indicate if changes were made. The images or other third party material in this article are included in the article's Creative Commons licence, unless indicated otherwise in a credit line to the material. If material is not included in the article's Creative Commons licence and your intended use is not permitted by statutory regulation or exceeds the permitted use, you will need to obtain permission directly from the copyright holder. To view a copy of this licence, visit http://creativecommons.org/licenses/by/4.0/. 
cost and lack of data demonstrating its efficacy and safety profile. The purpose of this retrospective review was to evaluate the safety and efficacy profile of $\mathrm{EVOH}$ in the treatment of peripheral vascular conditions and contribute the results of this retrospective review to an existing literature.

\section{Methods}

Institutional database was retrospectively reviewed to identify all patients who were treated with the use of EVOH between October 2010 and October 2017. We excluded cases involving nonvascular, neurologic, ophthalmologic, otolaryngologic or head-neck pathologies. The study was approved by the Institutional Review Board. All the patients had provided informed consent. From our database, we obtained demographic data, technical and clinical success rates, and procedure-related details, including embolic agents used, complications (Cx), and clinical outcomes.

\section{Embolization technique}

Standard EVOH embolization techniques were strictly employed as previously described in detail (Guimaraes \& Wooster, 2011; Kilani, 2015). The desired targets of embolization were approached with DMSO compatible microcatheters.

\section{Study endpoints}

Technical success (TS) was defined as the lack of active contrast extravasation beyond the site of embolization, and as elimination of flow to the aneurysmal sac or absence of residual endoleak in cases of endoleak embolization along with an absence of non-target embolization. Clinical success (CS) in cases of endoleak embolization was defined as decrease or stabilization of aneurysm size on a post embolization CT. Clinical success in cases other than endoleak embolization was defined as the resolution of signs and symptoms within 30 days of embolization and without major procedure-related complications. Embolizations requiring multiple sessions such as venous malformations (VM) or endoleaks were considered separate cases for a given patient, and not classified as clinical failures. Determination of success rates and complications are consistent with definitions put forth by the Society of Interventional Radiology Committee and CIRSE. (Angle et al., 2010; CIRSE, 2017)

\section{Results}

Over a period of 7 years, we identified 43 patients who underwent embolization with $\mathrm{EVOH}$ for peripheral vascular pathologies. These 43 patients underwent a total of 54 embolization procedures that met the inclusion criteria. The incongruent number of cases compared to number of patients was due to multiple embolization sessions for
Table 1 Patient demographic and case etiologies $(n=54)$

\begin{tabular}{ll}
\hline Patients $(n=43)$ & $33(76 \%)$ \\
\hline Male & $10(24 \%)$ \\
Female & $57.07( \pm 22$ years \\
Mean age & Standard Deviation) \\
Cases ( $n=54)$ & Frequency \\
Type II endoleak & 18 \\
Peripheral AVM & 14 \\
Pseudoaneurysm & 11 \\
Peripheral VM & 4 \\
Peripheral AV fistula & 2 \\
Yttrium-90 angiography mapping & 2 \\
Malignancy & 1 \\
Peripheral aneurysm & 1 \\
Acute gastrointestinal hemorrhage & 1 \\
\hline
\end{tabular}

several patients. Such cases included: VMs $(n=2)$, AVMs ( $n=9$ among 3 patients), and EL-2 ( $n=10$ procedures for 5 patients). The case etiologies are summarized in Table 1. The choice of embolic agents and viscosity of $\mathrm{EVOH}$ was up to the board-certified interventional radiologist's discretion. The indication for embolization, amount and concentration of $\mathrm{EVOH}$, prior embolization, and prior embolic agents are listed in Table 2. The majority of

Table 2 Features of cases treated with EVOH $(n=54)$

\begin{tabular}{|c|c|}
\hline \multicolumn{2}{|l|}{ Indications for treatment (\%) } \\
\hline Primary treatment & 44 (81.4\%) \\
\hline Pre-surgical devascularization & $5(9.2 \%)$ \\
\hline Palliative or symptomatic relief & $5(9.2 \%)$ \\
\hline Mean volume of EVOH & $2.2 \mathrm{ml} \pm 2.3$ \\
\hline \multicolumn{2}{|l|}{ Type of EVOH concentration used (\%) } \\
\hline 18 & $13(24 \%)$ \\
\hline 34 & $35(65 \%)$ \\
\hline Both & $6(11 \%)$ \\
\hline \multicolumn{2}{|c|}{ Cases with prior embolization and type of agents used (\%) } \\
\hline No prior treatment & $32(59.2 \%)$ \\
\hline Onyx & $9(16.6 \%)$ \\
\hline Coils & $5(9.2 \%)$ \\
\hline Coils + another agent & $5(9.2 \%)$ \\
\hline+ Onyx & 2 \\
\hline+ Thrombin & 1 \\
\hline + Gel foam & 1 \\
\hline+ Gel foam \& Onyx & 1 \\
\hline Gel foam & $1(1.8 \%)$ \\
\hline Onyx $+n$-butyl cyanoacrylate (NBCA) & $1(1.8 \%)$ \\
\hline Microspheres & $1(1.8 \%)$ \\
\hline
\end{tabular}


Table 3 Adjunctive embolic agents that were used with EVOH

\begin{tabular}{ll}
\hline Agent & Frequency (\%) \\
\hline None (EVOH only) & $34(62.9)$ \\
Coils & $12(22.2)$ \\
N-butyl cyanoacrylate (NBCA) & $4(7.4)$ \\
Sotradecol foam & $2(3.7)$ \\
Embospheres & $1(1.8)$ \\
Coils \& Gel foam & $1(1.8)$ \\
\hline
\end{tabular}

cases (62.5\%) used EVOH without any adjunct embolic material. The adjunct embolic agent used are shown in Table 3. The embolic agents are categorized by etiology in Table 4.

The patient characteristics, presenting symptoms/ signs, embolization targets, EVOH concentrations, adjunct embolic agents, procedure details, outcomes are shown in Table 5 for the patients with endoleak embolization; Table 6 for the patients with AVM embolization; Table 7 for the patients with PSA embolization; and Table 8 for patients who underwent embolization for the remaining etiologies. Overall post embolization TS rate was $100 \%$. The CS rate was $89 \%$, which excluded patients lost to follow up and patients who underwent surgical resection after embolization. No events of nontarget embolization (NTE) or other complications were noted. The loss to follow (LTF) up rate including those who received surgical resection after embolization was $16 \%$ (9/54). The mean follow-up period was 134 days (range, 30 to 522 days).

\section{Discussion}

This retrospective review showed that $\mathrm{EVOH}$ is a safe embolic agent and has a valuable role in the treatment of various peripheral vascular pathologies including, but not limited to type II endoleaks, AVMs, VMs, postoperative peripheral PSAs, and arteriovenous (AV) fistulas.

Traditionally, administration of $\mathrm{EVOH}$ is considered technically complex and difficult to control. A steep learning curve of the embolization technique can result in an incomplete or nontarget embolization. This has likely limited the adoption of this embolic agent in the peripheral applications. Over a short period of use of $\mathrm{EVOH}$ at the current institution, high TS rates of EVOH embolization were achieved. The experience also suggested that EVOH can be safely used in the periphery.

Well-known within the literature, the delivery of Onyx involves a uniquely meticulous process (Guimaraes \& Wooster, 2011; Kilani, 2015). Unlike $n$-butyl cyanoacrylate glue (NBCA), this nonadhesive agent does not attach to endothelium or microcatheters and has been shown to induce a very mild regional inflammatory reaction (Murayama et al., 1998; Duffner et al., 2002). Upon contact with the blood, slow solidification of $\mathrm{EVOH}$ in a centripetal fashion endows it with a foam like consistency. These properties allow slow, progressive and controlled deployment of the EVOH at the desired location leading to complete occlusion of desired targets of various sizes and shapes. Being a non-absorbable embolic agent, an irreversible target occlusion is achieved for permanent treatment of peripheral pathologies. However, permanent occlusion also raises the fear of healthy tissue necrosis in

Table 4 Embolization agent based on case etiology

\begin{tabular}{|c|c|}
\hline Etiology ( $n=$ number of cases) & N (\%) Embolic agents \\
\hline \multirow[t]{2}{*}{ Type II endoleak ( $n=18)$} & 14 (78\%) EVOH alone \\
\hline & 4 (22\%) EVOH + coils \\
\hline \multicolumn{2}{|l|}{ Peripheral AVM $(n=14)$} \\
\hline \multirow[t]{2}{*}{ Pelvic / Uterine AVMs $(n=7)$} & $6 \mathrm{EVOH}$ alone \\
\hline & $1 \mathrm{EVOH}+$ coils \\
\hline \multirow[t]{2}{*}{ Extremity AVMs $(n=7)$} & $5 \mathrm{EVOH}$ alone \\
\hline & $2 \mathrm{EVOH}+$ Sotradecol foam \\
\hline \multirow[t]{2}{*}{ Pseudoaneurysm ( $n=11)$} & $5 \mathrm{EVOH}+$ coils \\
\hline & $6 \mathrm{EVOH}$ alone \\
\hline Peripheral venous malformation $(n=4)$ & $4 \mathrm{EVOH}+\mathrm{NBCA}$ \\
\hline \multirow[t]{2}{*}{ Peripheral arteriovenous fistula $(n=2)$} & $1 \mathrm{EVOH}$ alone \\
\hline & 1 EVOH + Coils \& Gelfoam \\
\hline Yttrium-90 angiography mapping $(n=2)$ & $2 \mathrm{EVOH}$ alone \\
\hline Malignancy $(n=1)$ & $1 \mathrm{EVOH}+$ Embosperes \\
\hline Peripheral aneurysm $(n=1)$ & $1 \mathrm{EVOH}$ alone \\
\hline Acute gastrointestinal hemorrhage $(n=1)$ & $1 \mathrm{EVOH}$ alone \\
\hline
\end{tabular}




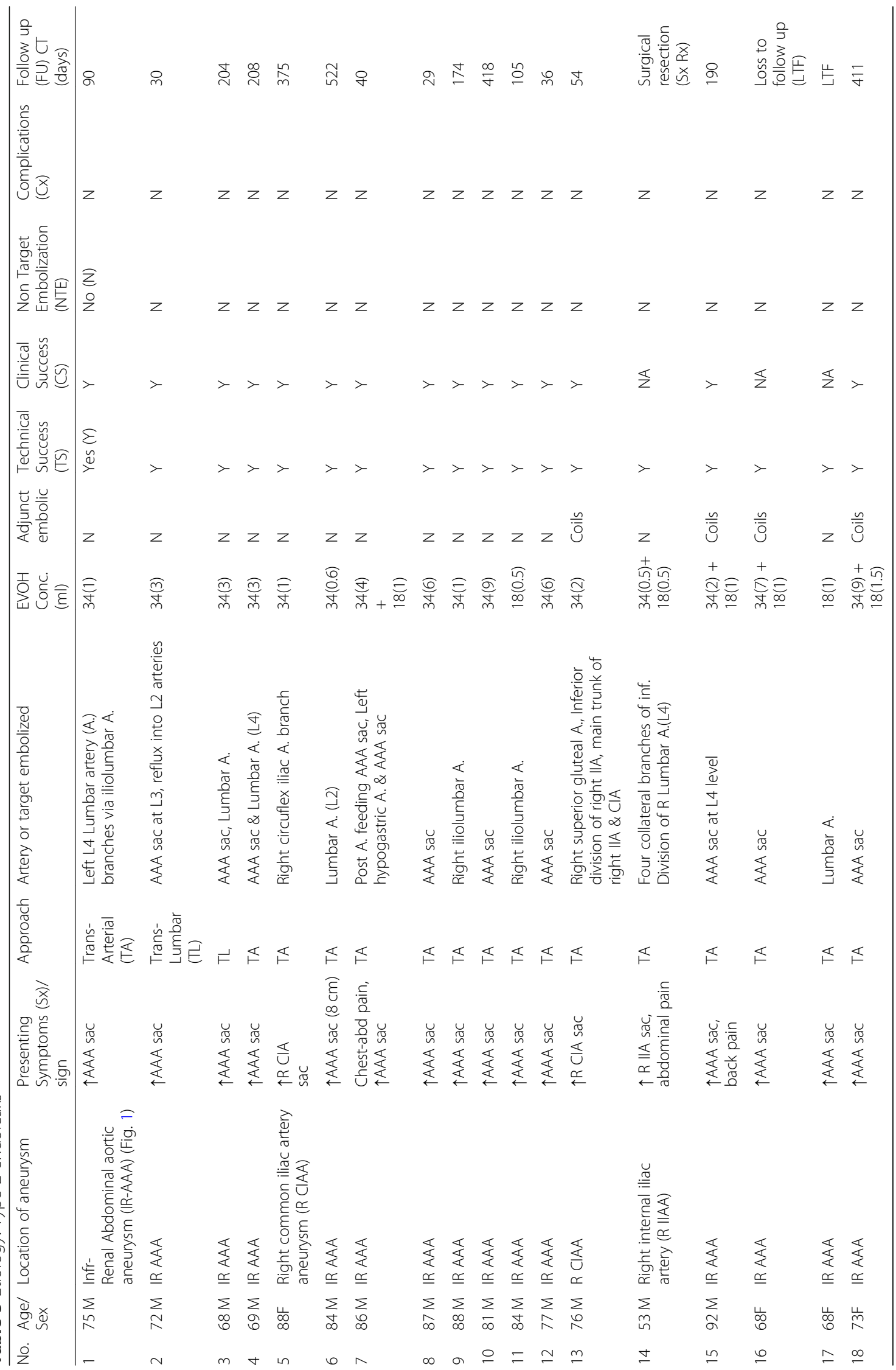




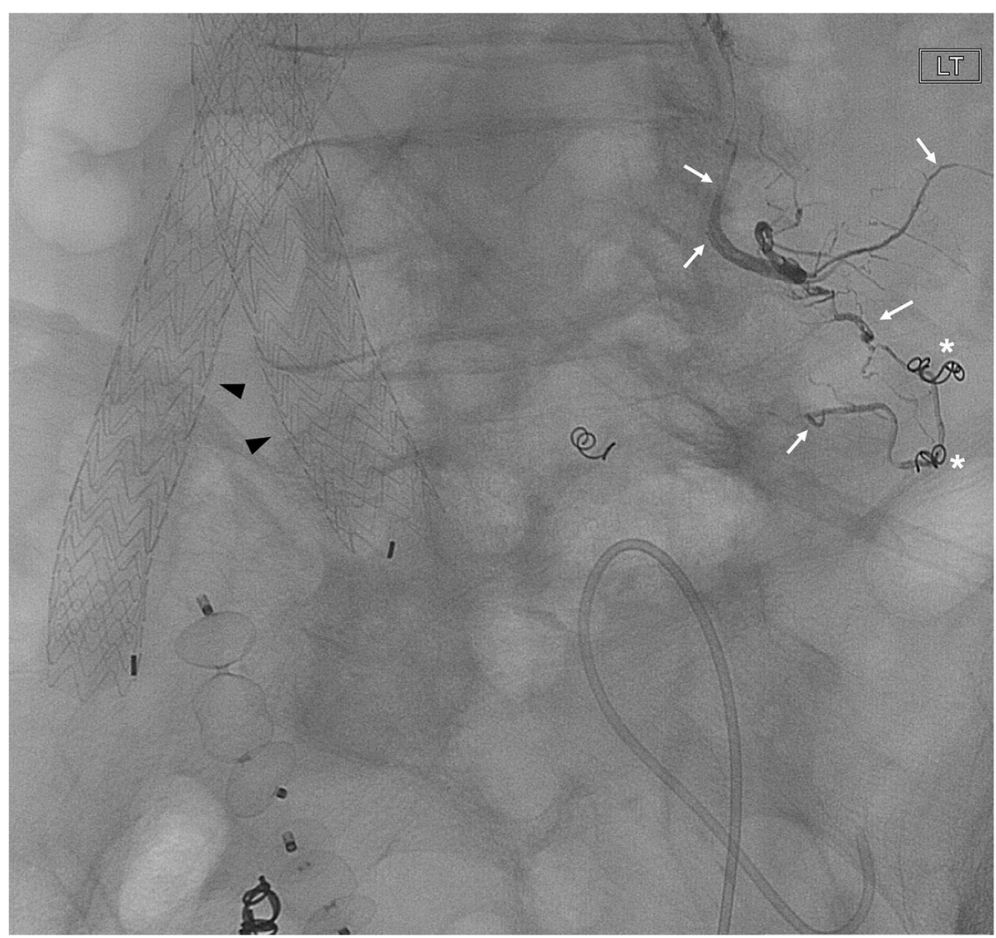

Fig. 175 year-old male with an enlarging AAA sac status post endovascular repair (arrowhead). Fluoroscopic image demonstrates EVOH (Onyx 34) embolization of a third order branch of $L 4$ Lumbar artery (arrows) which was leading to type II endoleak. Prior attempt of coil embolization of this endoleak was unsuccessful (asterisk)

Table 6 Etiology: Arteriovenous malformations

\begin{tabular}{|c|c|c|c|c|c|c|c|c|c|c|c|}
\hline No. & $\begin{array}{l}\text { Age/ } \\
\text { Sex }\end{array}$ & $\begin{array}{l}\text { Location } \\
\text { of AVM }\end{array}$ & $\begin{array}{l}\text { Presenting } \\
\text { Sx/sign }\end{array}$ & Artery or target embolized & $\begin{array}{l}\text { EVOH } \\
\text { Conc } \\
\text { (ml) }\end{array}$ & $\begin{array}{l}\text { Adjunct } \\
\text { embolic }\end{array}$ & TS & CS & NTE & $C x$ & $\begin{array}{l}\text { FU } \\
\text { (Days) }\end{array}$ \\
\hline 1 & $22 \mathrm{~F}$ & Uterus & $\begin{array}{l}\uparrow \text { vaginal } \\
\text { bleeding }\end{array}$ & Right uterine A. & $18(0.3)$ & $N$ & Y & Y & $\mathrm{N}$ & N & 90 \\
\hline 2 & $40 \mathrm{~F}$ & Uterus (Fig. 2) & $\begin{array}{l}\uparrow \text { vaginal } \\
\text { bleeding }\end{array}$ & Right \& left uterine A. & $18(0.9)$ & $N$ & Y & Y & $\mathrm{N}$ & N & 90 \\
\hline 3 & $35 \mathrm{~F}$ & Uterus & $\begin{array}{l}\uparrow \text { vaginal } \\
\text { bleeding }\end{array}$ & Right uterine A. & $18(0.1)$ & $N$ & Y & Y & $\mathrm{N}$ & N & 30 \\
\hline 4 & $48 \mathrm{~F}$ & Left pelvic cavity & Pelvic pain & $\begin{array}{l}\text { Two branches of ant division of left internal } \\
\text { iliac artery (IIA)\& one branch of uterine artery }\end{array}$ & $34(0.6)$ & $\mathrm{N}$ & Y & N & $\mathrm{N}$ & N & 90 \\
\hline 5 & $49 \mathrm{~F}$ & Left pelvic cavity & Pelvic pain & $\begin{array}{l}\text { Third order branch of left external pudendal } \\
\text { A. and a branch of anterior division of left IIA }\end{array}$ & $34(1)$ & $\mathrm{N}$ & Y & Y & $\mathrm{N}$ & N & 75 \\
\hline 6 & $49 \mathrm{~F}$ & Left pelvic cavity & Pelvic pain & Four distal branches of left IIA. & $34(1.5)$ & Coil & Y & NA & N & $\mathrm{N}$ & LTF \\
\hline 7 & $50 \mathrm{~F}$ & Left pelvic cavity & Pelvic pain & Branches of anterior division of left IIA & $34(1)$ & Coil & Y & NA & $\mathrm{N}$ & N & LTF \\
\hline 8 & $40 \mathrm{~F}$ & $\begin{array}{l}\text { Left upper } \\
\text { extremity }\end{array}$ & Pain/mass & Distal branches of ulnar A. & $34(1.5)$ & $\mathrm{N}$ & Y & NA & N & $\mathrm{N}$ & $S x \operatorname{Rx}$ \\
\hline 9 & $61 \mathrm{M}$ & $\begin{array}{l}\text { Right lower } \\
\text { extremity }\end{array}$ & Calf pain & Peroneal A. branches & $34(0.6)$ & $\mathrm{N}$ & Y & Y & $\mathrm{N}$ & N & 439 \\
\hline 10 & $61 \mathrm{M}$ & $\begin{array}{l}\text { Right lower } \\
\text { extremity }\end{array}$ & Calf pain & Proximal PT branches & $18(0.5)$ & $\mathrm{N}$ & Y & N & $\mathrm{N}$ & N & 35 \\
\hline 11 & $35 \mathrm{~F}$ & Calf; Congenital & Chronic calf pain & Muscular branch of peroneal A. & $34(0.3)$ & $\mathrm{N}$ & Y & Y & $\mathrm{N}$ & N & 77 \\
\hline 12 & $35 \mathrm{~F}$ & Calf; Congenital & Chronic calf pain & AVM & $18(1.3)$ & Sotradecol foam & Y & Y & $\mathrm{N}$ & $\mathrm{N}$ & 70 \\
\hline 13 & $35 \mathrm{~F}$ & Calf; Congenital & Chronic calf pain & AVM & 18(3) & Sotradecol foam & Y & Y & $\mathrm{N}$ & N & 79 \\
\hline 14 & $72 \mathrm{~F}$ & R thigh/ buttock & Pain, discomfort & Three branches of $R$ profunda femoris $A$. & $34(0.5)$ & $\mathrm{N}$ & Y & Y & $\mathrm{N}$ & $\mathrm{N}$ & 90 \\
\hline
\end{tabular}




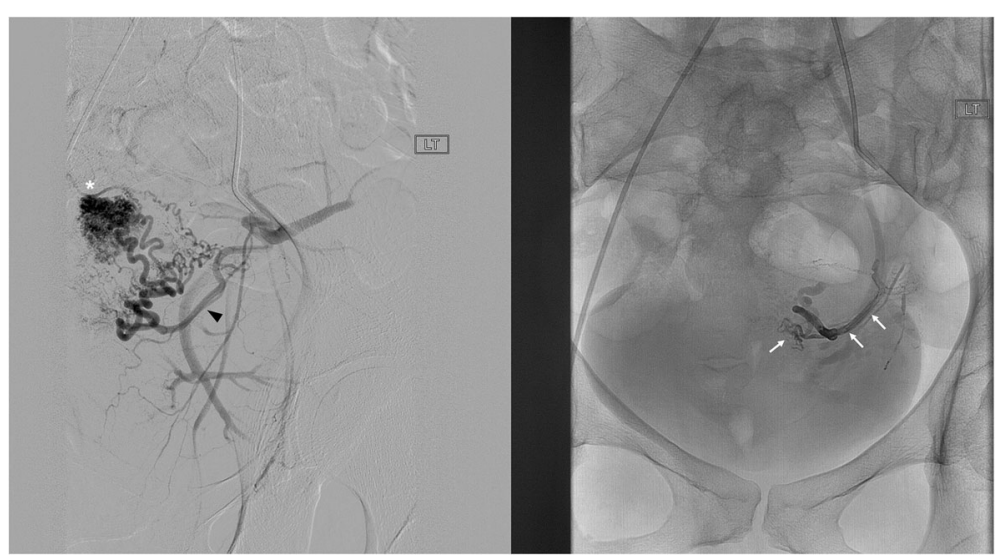

Fig. 2 a 40 year old female who presented with heavy vaginal bleeding. Fluoroscopic image demonstrates a high flow, large uterine AVM (asterisk) supplied by a left uterine artery (arrowhead) and drained by veins. b. Fluoroscopic image shows successful EVOH embolization of the left uterine artery and non-opacification of AVM (arrow)

the event of nontarget embolization. As per authors' experience, methodical techniques, adequate training and appropriate choice of $\mathrm{EVOH}$ viscosity play an important role for safe embolization and avoidance of complications. The EVOH with higher viscosity (Onyx 34) was chosen when the microcatheter tip was near the target and controlled injection was needed to prevent distal embolization. The lower viscosity EVOH (Onyx 18) was used when the target remained distant from the microcatheter tip or reaching the target proved challenging secondary to vessel tortuosity or increased vessel length. Lower viscosities of EVOH are safe for embolization of end arteries (Guimaraes \& Wooster, 2011; Kilani, 2015). The size and flow rate of the target vessel was also considered in choosing the EVOH concentration.
Early literature reported higher rates $(80 \%)$ of recanalization when only afferent arteries of the type 2 endoleaks (EL-2) were embolized with coils, without embolization of aneurysmal sacs, using transarterial (TA) approach. This retrospective study reported statistically significant lower rates (8\%) of recanalization when aneurysmal sacs were embolized with coils using the translumbar approach (Baum et al., 2002). Recanalization through the interstices of coils could explain the incidence of recanalization with either approach. Another large $(n=84)$ retrospective study reported no statistically significant difference in the clinical success (i.e. absence of endoleak or aneurysm enlargement) rates of TA or TL approaches. In this study the TA approach included embolization of entire aneurysmal sac along with its

Table 7 Etiology: Pseudoaneurys

\begin{tabular}{|c|c|c|c|c|c|c|c|c|c|c|}
\hline No. & $\begin{array}{l}\text { Age/ } \\
\text { Sex }\end{array}$ & Presenting Sx/sign & Artery or target embolized & $\begin{array}{l}\text { Onyx } \\
\text { Conc (ml) }\end{array}$ & $\begin{array}{l}\text { Adjunct } \\
\text { embolic }\end{array}$ & TS & CS & NTE & Cx & $\begin{array}{l}\text { FU CT } \\
\text { Days }\end{array}$ \\
\hline 1 & $61 \mathrm{M}$ & Abdominal pain & Inferior pancreatico-duodenal A. & 18(1) & $\mathrm{N}$ & Y & Y & N & N & 30 \\
\hline 2 & $28 \mathrm{~F}$ & Abdominal pain (Fig. 3) & Left hepatic A. branch & $18(0.6)$ & N & Y & Y & $\mathrm{N}$ & N & 30 \\
\hline 3 & $34 \mathrm{M}$ & Abdominal pain & R hepatic A. & $34(0.5)$ & Coils & Y & Y & N & N & 37 \\
\hline 4 & $53 \mathrm{M}$ & Hematuria s/p L partial nephrectomy (Fig. 4) & Third order branch of left renal A. & $34(1)$ & N & Y & Y & N & N & 31 \\
\hline 5 & $38 \mathrm{~F}$ & R pelvic pain $s / p$ total abdominal hysterectomy & Distal right uterine $\mathrm{A}$. & $34(0.8)$ & Coils & Y & Y & N & N & 190 \\
\hline 6 & $29 M$ & Asymptomatic, US surveillance $s / p$ renal Bx & Right renal A. & $34(0.5)$ & Coils & Y & Y & N & N & 181 \\
\hline 7 & $74 \mathrm{M}$ & $\begin{array}{l}\text { Hemodynamically unstable s/p L radical } \\
\text { nephrectomy }\end{array}$ & Left renal A. & $34(0.3)$ & N & Y & Y & $\mathrm{N}$ & N & 248 \\
\hline 8 & $73 \mathrm{M}$ & Abdominal pain $s / p$ right renal tumor resection & $\begin{array}{l}\text { Two third order branches of inferior } \\
\text { division of right renal A. }\end{array}$ & $34(0.6)$ & N & Y & Y & N & N & 235 \\
\hline 9 & 29 M & $\begin{array}{l}\text { Numbness \& loss of dorsiflexion s/p stab injury } \\
\text { to anterior calf }\end{array}$ & Proximal anterior tibial A. & $34(0.4)$ & Coils & Y & Y & N & N & 30 \\
\hline 10 & $22 \mathrm{M}$ & $\begin{array}{l}\text { Right side hemothorax and pneumothorax after } \\
\text { stab injury }\end{array}$ & Right upper lobe pulmonary A. & $34(3)$ & Coils & Y & Y & N & N & 30 \\
\hline 11 & $63 \mathrm{M}$ & Active intraperitoneal bleeding & Superior mesenteric A. & 18(6) & $\mathrm{N}$ & Y & Y & $\mathrm{N}$ & $\mathrm{N}$ & 31 \\
\hline
\end{tabular}




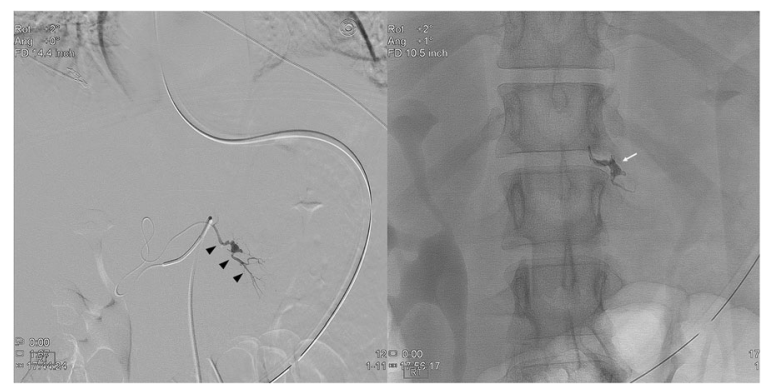

Fig. 3 a 28 year-old male presenting with RUQ abdominal pain. Selective angiogram of a left hepatic artery branch demonstrates a PSA (arrowhead). b. Fluoroscopic image shows EVOH (Onyx 18) embolization leading to occlusion of afferent, efferent vessel and sac of PSA (arrow)

afferent artery. The clinical success rates were 78\% (18/ 23) when aneurysmal sac and afferent arteries were embolized with coils using TA approach, and 72\% (45/ 62) when aneurysmal sac was embolized with coils/ NBCA using TL approach. (Stavropoulos et al., 2009) The study reported a complication i.e. nontarget embolization which could be related to the need for a rapid injection of NBCA to prevent its adhesion to the vessel or microcatheter tip. Another recent retrospective study showed no significant difference in aneurysm sac growth, persistent EL-2 or complications between TA and TL approaches. The study also reported technical success rate in $89 \%$ cases and absence of endoleak recurrence in $70 \%$ cases. The embolic agents used were

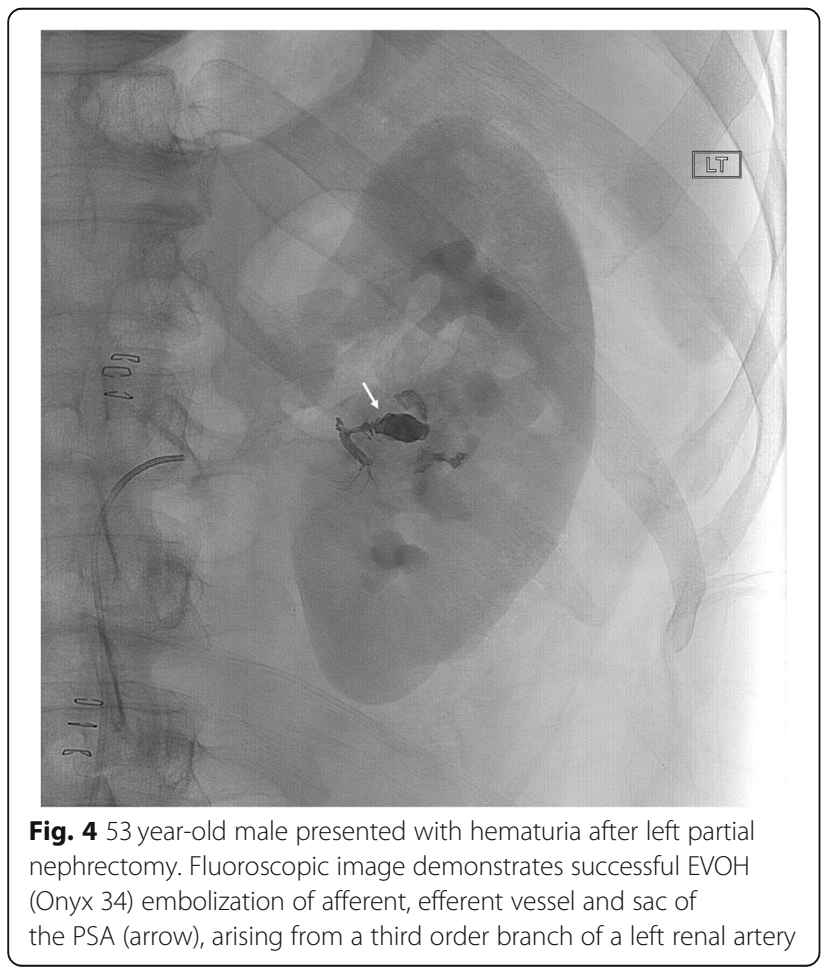

NBCA, NBCA plus coils, or coils only (Yang et al., 2016). Few other studies reported good technical and clinical outcomes when EL-2 were embolized with $\mathrm{EVOH}$ or EVOH with other agents (Massis et al., 2012; Khaja et al., 2013; Marcelin et al., 2017; Abularrage et al., 2012). As per the current institutional experience, EVOH alone was sufficient to effectively occlude the afferent vessels as well as aneurysmal sac in $14 / 18$ i.e. $78 \%$ of EL- 2 cases. The 12 of total 18 EL-2 cases had prior endovascular interventions. Out of these twelve persistent EL-2 cases, EVOH alone was suffiecient in nine (75\%) cases. In the remaining cases of new EL-2 $(n=1)$ and persistant EL-2 $(n=3)$, coils were used along with $\mathrm{EVOH}$ to occlude the aneurysmal sac. The approach for the embolization of EL-2 were either TA (89\%) and TL (11\%) with standard procedural steps as described before. (Bryce et al., 2018) The immediate post-embolization TS rate and CS rates were $100 \%$. These results continue to support the use of $\mathrm{EVOH}$ in treatment of persistent EL-2 which are refractory to other embolic agents. The high TS rates are due to an ability of $\mathrm{EVOH}$ to penetrate and occlude afferent/efferent vessels and aneurysmal sacs of various sizes and shapes. Also the results such as absence of nontarget embolization or complications were similar to the results previously reported (Khaja et al., 2013; Marcelin et al., 2017; Abularrage et al., 2012).

For the treatment of new EL-2, the TA approach was preferred when access and embolization of aneurysmal sac via afferent vessels were possible. Once in the aneurysmal sac, whenever required based on the sac size, we first used coils to fill the aneurysmal sacs. Then $\mathrm{EVOH}$ was injected under fluoroscopic guidance until the proximal portions of efferent vessels were completely occluded. Then proximal portions of afferent vessels were occluded with $\mathrm{EVOH}$ while slowly withdrawing the microcatheter. When accessing an aneurysmal sac via afferent vessel using TA approach was not possible, the TL approach was used to directly enter the aneurysmal sac and EVOH was injected until aneurysmal sac and proximal portions of afferent and efferent vessel were completely occluded. In the cases of recurrent EL-2 ( $n=$ 12 ), the aneurysmal sacs were already partially occluded with prior embolic material, hence in most of these cases (75\%) EVOH alone was sufficient to achieve complete occlusion. The preference of approach and technique of embolization were similar to the management of a new EL-2 as described before. As per this experience, EVOH was an ideal embolic agent when the target cannot be directly catheterized, for example if the route was tortuous, small in caliber or distal to negotiate with a microcatheter. In complex cases of EL-2 when access to culprit afferent vessel by $\mathrm{TA}$ approach or access to 
Table 8 All remaining etiologies

\begin{tabular}{|c|c|c|c|c|c|c|c|c|c|c|c|}
\hline No. & $\begin{array}{l}\text { Age/ } \\
\text { Sex }\end{array}$ & Location & Presenting Sx/sign & $\begin{array}{l}\text { Artery or target } \\
\text { embolized }\end{array}$ & $\begin{array}{l}\text { Onyx } \\
\text { Conc } \\
\text { (ml) }\end{array}$ & $\begin{array}{l}\text { Adjunct } \\
\text { embolic }\end{array}$ & TS & CS & NTE & $C x$ & $\begin{array}{l}\text { FU } \\
\text { Days }\end{array}$ \\
\hline \multicolumn{12}{|c|}{ Peripheral arteriovenous fistula (AVF) } \\
\hline 1 & $28 \mathrm{M}$ & $\begin{array}{l}\text { Pelvic AVF after gun shot injury s/p } \\
\text { right IIA ligation \& gelfoam embolization } \\
\text { of post division of left IIA. }\end{array}$ & Abdominal bleeding & Middle sacral A. & 18(1) & $\begin{array}{l}\text { Coils \& } \\
\text { gelfoam }\end{array}$ & Y & Y & N & $\mathrm{N}$ & 42 \\
\hline 2 & $80 \mathrm{~F}$ & Right lower extremity (RLE) & RLE tissue loss & $\begin{array}{l}\text { Three branches of } \\
\text { profunda femoris }\end{array}$ & $34(1.5)$ & N & Y & $\mathrm{N}$ & N & N & 56 \\
\hline \multicolumn{12}{|c|}{ Venous malformations (VM) } \\
\hline 1 & $22 \mathrm{M}$ & Chest wall & $\begin{array}{l}\text { Pain and discoloration } \\
\text { of right chest wall }\end{array}$ & VM & $\begin{array}{l}34 \\
(1.3)\end{array}$ & NBCA & Y & Y & N & N & 105 \\
\hline 2 & $22 \mathrm{M}$ & Chest wall & $\begin{array}{l}\text { Pain and discoloration } \\
\text { of right chest wall }\end{array}$ & VM & $18(3)$ & NBCA & Y & Y & N & N & 30 \\
\hline 3 & $61 \mathrm{M}$ & Right shoulder, back, pectoralis (Fig. 5) & $\begin{array}{l}\text { Swelling of right } \\
\text { shoulder, axilla \& back }\end{array}$ & VM & $\begin{array}{l}34(1.5) \\
+ \\
18(4.5)\end{array}$ & NBCA & Y & Y & N & N & $\begin{array}{l}\text { Sx } \\
\text { Rx }\end{array}$ \\
\hline 4 & $29 \mathrm{M}$ & Plantar 3rd/4th intermetatarsal region & Left plantar foot pain & VM & 18(1) & NBCA & Y & Y & N & N & $\begin{array}{l}\text { Sx } \\
\text { Rx }\end{array}$ \\
\hline \multicolumn{12}{|c|}{ latrogenic arterial rupture } \\
\hline 1 & $52 \mathrm{M}$ & Intra-abdominal & $\begin{array}{l}\text { Metastatic colorectal } \\
\text { carcinoma involving } \\
\text { liver, Y-90 planning }\end{array}$ & Right Gastric A. & $34(0.1)$ & $\mathrm{N}$ & Y & Y & $\mathrm{N}$ & N & 37 \\
\hline 2 & $63 \mathrm{M}$ & Intra-abdominal & $\begin{array}{l}\text { Metastatic colorectal } \\
\text { carcinoma involving } \\
\text { liver, Y-90 planning }\end{array}$ & Right Gastric A. & $34(0.5)$ & N & Y & Y & N & N & 298 \\
\hline \multicolumn{12}{|c|}{ Malignancy } \\
\hline 1 & $54 \mathrm{M}$ & Right arm sarcoma (Fig. 6) & Right arm mass & $\begin{array}{l}\text { Branches of } \\
\text { brachial A. and } \\
\text { profunda radialis } \\
\text { A. }\end{array}$ & $34(6)$ & Embospheres & Y & Y & N & N & $\begin{array}{l}\text { Sx } \\
\text { Rx }\end{array}$ \\
\hline \multicolumn{12}{|c|}{ Peripheral aneurysm } \\
\hline 1 & $83 \mathrm{M}$ & Popliteal A. & $\begin{array}{l}\text { Enlarging left popliteal } \\
\text { A. aneurysm sac }\end{array}$ & $\begin{array}{l}\text { Left popliteal A. } \\
\text { aneurysm sac }\end{array}$ & $34(3)$ & N & Y & Y & N & N & 227 \\
\hline \multicolumn{12}{|c|}{ Acute gastrointestinal hemorrhage } \\
\hline 1 & $57 \mathrm{M}$ & Duodenal bulb ulcer (Fig. 7) & Hematemesis \& malena & $\begin{array}{l}\text { Proximal gastro- } \\
\text { duodenal } \mathrm{A} \text {. }\end{array}$ & $34(0.5)$ & N & Y & Y & N & N & 30 \\
\hline
\end{tabular}

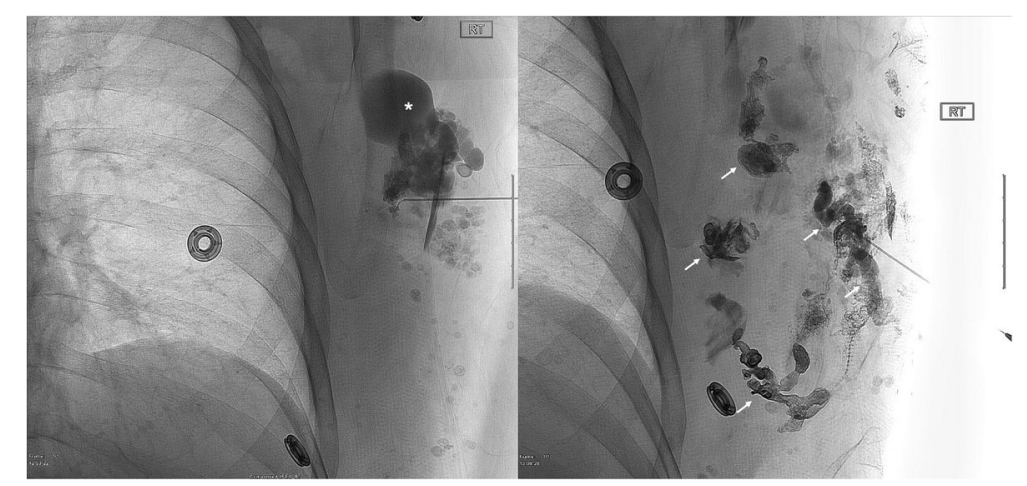

Fig. 5 a 61 year-old male presented with swelling involving the right shoulder, and pectoral region secondary to VM. Fluoroscopic image demonstrates a large VM (asterisk). b. Fluoroscopy image after percutaneous embolization shows filling of venous lakes in the VM by embolic agents (arrows) 


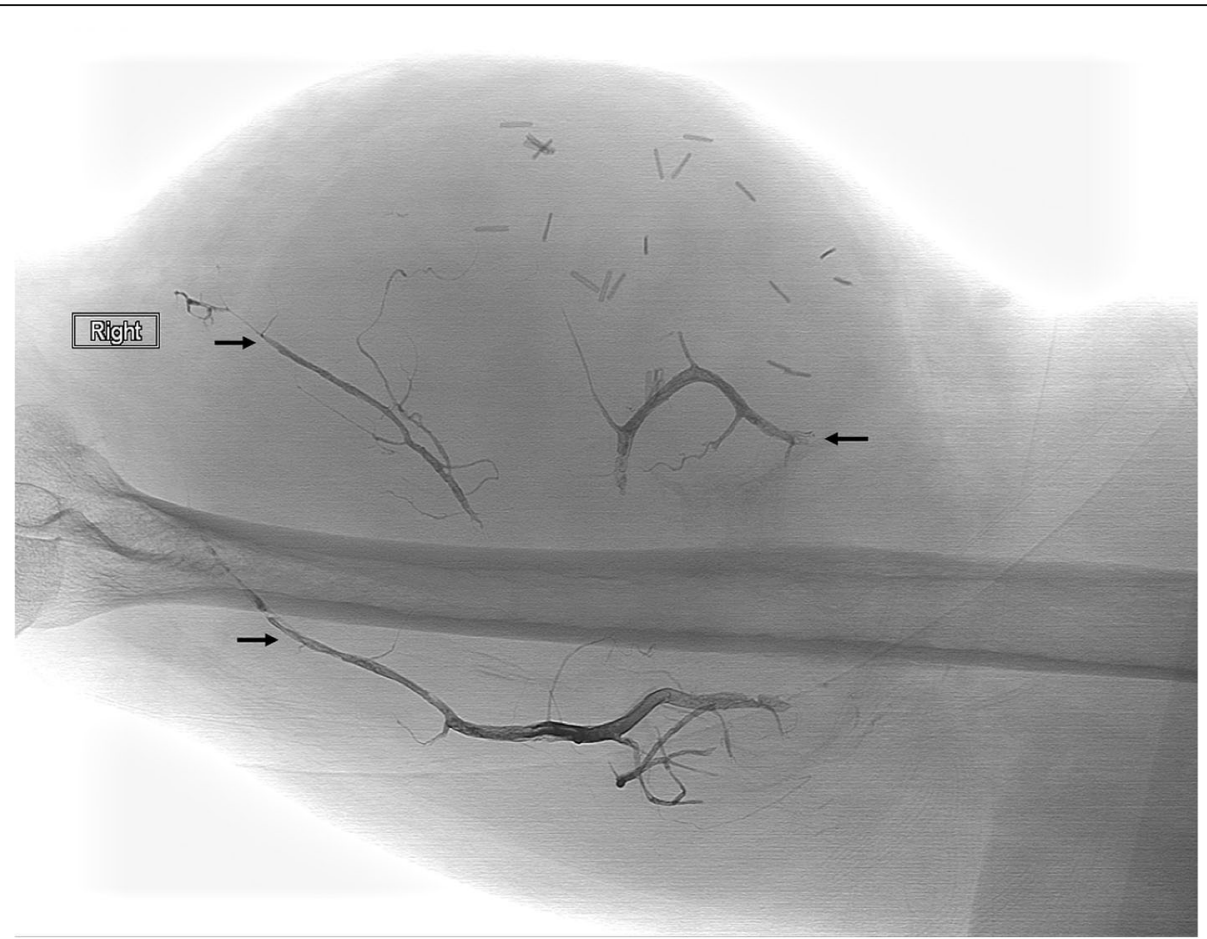

Fig. 6 54-year-old male presented for devascularization of right arm sarcoma prior to surgical resection. Fluoroscopic image demonstrates filling of arterial branches in the upper arm mass by EVOH (arrows) and paucity of vascularity following EVOH and embosphere embolization of the brachial artery branches

aneurysmal sac via TL approach were not possible, then low viscosity EVOH (Onyx 18) was injected in the proximal aspects of afferent vessels. Other endovascular approaches such as transcaval (Giles et al., 2015) and perigraft (Coppi et al., 2014), though not used in our study, can be useful.

Uterine AVMs are rare but potentially life threatening. Similar to a prior case series, this retrospective review showed 100\% TS and CS rates of EVOH embolization of three high flow AVMs in women of reproductive age group ( 22 to 40 years). At the current institution, the use of low viscosity EVOH (Onyx 18) allowed selective embolization of the niduses of uterine AVMs that were difficult to reach with the microcatheters. None of the patients underwent subsequent hysterectomy. There is no data reporting the most appropriate embolic agent to treat

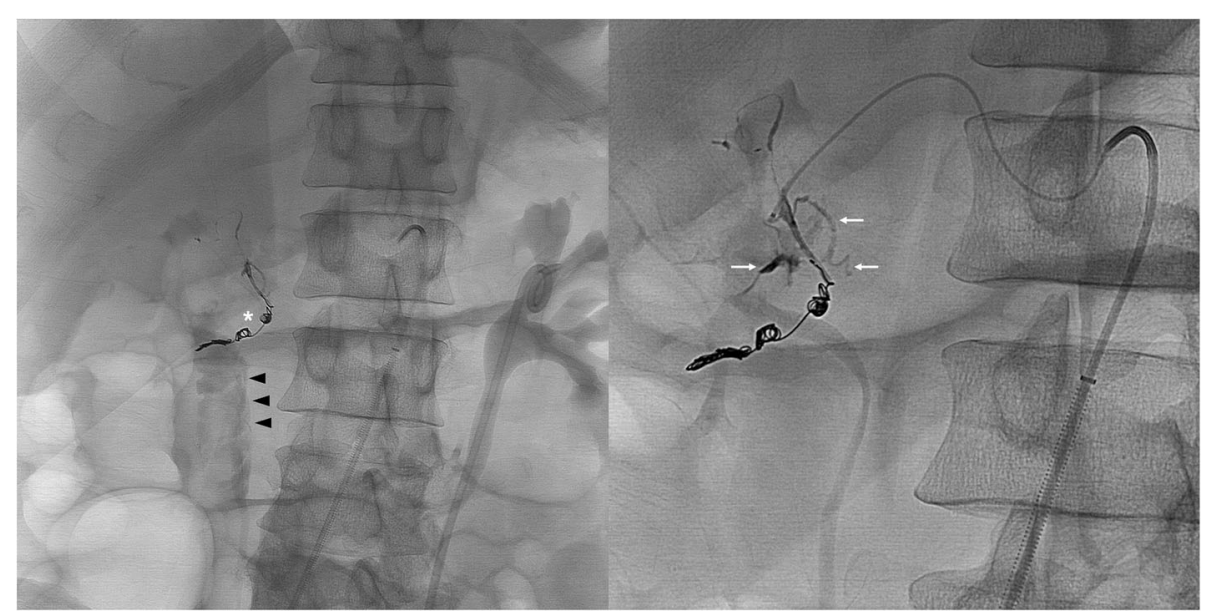

Fig. 7 a 57 year old male presented with hematemesis and melena. Fluoroscopic image demonstrates persistent active extravasation of the contrast into proximal duodenum (arrowhead) despite deployment of four fibered platinum detachable microcoils (asterisk). b The fluoroscopic image demonstrates selective angiography of gastroduodenal artery and absence of extravasation after EVOH embolization (arrow) 
uterine AVMs. The available data indicates that resorbable agents and coils are ineffective. (Barral et al., 2017)

$\mathrm{EVOH}$ is considered ideal for embolization of AVMs due to it's ability to penetrate and conform to the shapes of tortuous afferent arteries and variable nidus sizes. Being a non-adhesive agent, it allows precise positioning and control of the tip of the delivery microcatheters during the $\mathrm{EVOH}$ injections. The Interventionalist can interrupt the injection, reanalyze the $\mathrm{EVOH}$ cast and reinject at the new location to occlude a large AVM without filling the draining veins (Regine et al., 2015). A prior study has reported reflux of $\mathrm{EVOH}$ within the afferent artery during embolization of high flow AVM and nontarget embolization. This was attributed to complex angio-architecture, short arterial feeders close to parent arteries and poor radiopacity of earlier generation of $\mathrm{EVOH}$. During the final stages of EVOH injection in the afferent arteries, the pressure reaches critical threshold and $\mathrm{EVOH}$ can reflux into the afferent artery. However with continuous fluoroscopic monitoring, interventionalists can modulate the volume and rate of injection to effectively occlude the afferent artery and avoid the reflux. Also, the use of higher viscosity EVOH to embolize the afferent arteries of high flow AVMs can cause an instant onsite polymerization and occlusion. This can avoid the further passage of EVOH through fistulous component and venous reflux (Cantasdemir et al., 2012).

In this series, the complex or large venous malformations (VM) were percutaneously embolized with a combination of liquid embolic agents; NBCA for the superficial component and EVOH for the deeper component of VM (Fig. 2). As described in the recent literature (Salaskar et al., 2020), the use of $\mathrm{EVOH}$ is advantageous in the embolization of deeper parts of complex VM for several reasons. Being a nonadhesive agent, $\mathrm{EVOH}$ could be precisely delivered in the deeper aspects of VMs. After intravascular precipitation, the deeper aspect of VM retained a soft sponge-like consistency. This facilitated surgical handling during resection of VM. The use of EVOH embolization has been previously shown to be superior for surgical resection of AVMs when compared with NBCA embolization (Akin et al., 2003). EVOH was shown to incur minimal intra or perivascular inflammatory reaction (Murayama et al., 1998; Duffner et al., 2002). Similarly absence of inflammation facilitated safe surgical resection of complex VMs. To prevent non target embolization, high viscosity EVOH was used when preembolization venography of VM revealed contrast entry into the central veins. The conventional alcohol sclerotherapy of VM has side effects such as tissue swelling, mucosal blistering, necrosis, and neuropathy (Cantasdemir et al., 2012). None of these side effects were observed with the use of $\mathrm{EVOH}$.
Few case reports have described the use of $\mathrm{EVOH}$ in the treatment of renal PSAs and AV fistulas (Vanninen \& Manninen, 2007; Carberry et al., 2013; Zeleňák et al., 2009). In this series, four cases of post-surgical renal PSAs were successfully embolized, including an urgent case in which successful cessation of life threatening bleeding was achieved by EVOH embolization of a post nephrectomy PSA (Fig. 4). In these cases, EVOH embolization involved filling the afferent \& efferent arteries as well as the PSA sac. In order to prevent distal nontarget embolization, high viscosity EVOH was used.

EVOH embolization has also been used in the treatment of active gastrointestinal hemorrhage with good outcomes (Kolber et al., 2015; Lenhart et al., 2010). The results of one prior retrospective series demonstrated $100 \%$ TS rate without any complications in patients who underwent EVOH embolization for the treatment of persistent gastrointestinal bleeding despite endoscopic interventions (Lenhart et al., 2010). Unlike other embolic agents such as coils, EVOH polymerization does not depend on a functional coagulation cascade. This property is pivotal in controlling the active bleeding in patients with underlying coagulopathies (Müller-Wille et al., 2011; Carberry et al., 2013). In the management of iatrogenic \& traumatic arterial ruptures, EVOH was preferred to occlude the damaged target vessel which could not be catheterized directly. Also the ability to deploy $\mathrm{EVOH}$ without exerting any radial pressure to the damaged vessel walls makes EVOH an ideal agent.

Previously reported DMSO related side effects such as local pain after rapid injection of Onyx (Vanninen \& Manninen, 2007), foul breath, severe respiratory distress, pulmonary edema due to DMSO related oxygen desaturation (Pamuk et al., 2005; Murugesan et al., 2008), cardiovascular instability secondary to vasovagal reaction from irritation of nociceptive nerve fibers of intercostal arteries and/or aortic side branches by DMSO (Wildgruber et al., 2016) were not seen in this study group. As per the current experience, use of an appropriate amount of DMSO to adequately fill the lumen of the microcatheter can avoid these risks. The tantalum powder in the mixture of Onyx may cause streak artifacts on radiographic and CT images. This may hinder visualization of future recurrence or regional tissues (Jia et al., 2015). On MR images, EVOH appears hypointense and does not cause artifacts.

Prior study has reported longer fluoroscopy and procedure time with $\mathrm{EVOH}$ embolization when compared to those with NBCA embolization. This was attributed to the slow injection rate of $\mathrm{EVOH}$, however in our experience these are operator dependent. The slow, controlled injection of $\mathrm{EVOH}$ is in fact desirable for precise and effective embolization (Velat et al., 2008). 
The perceived high cost of EVOH embolization may limit its adoption. A vial of EVOH costs approximately $\$ 2000$ USD. A vial of NBCA is approximately the same cost at the institute. The average cost of total $\mathrm{EVOH}$ used per case is estimated to be approximately $\$ 4000$ USD at our institute. The use of EVOH can sometimes leads to reduction in the use of coils, thereby leads to cost savings. However, if multiple vials of $\mathrm{EVOH}$ or coils are required for the procedure, the cost advantage can be quickly lost. Therefore each case should be prudently planned to preserve resources.

The limitations of this study are its retrospective nature and small sample size. Ideally the safety and efficacy of EVOH embolization should continue to be evaluated by comparing it to standard embolic therapies in prospective studies.

\section{Conclusion}

This single institutional experience supports the safety and efficacy of EVOH embolization in the treatment of various peripheral vascular pathologies.

\section{Abbreviations}

EVOH: Ethylene vinyl alcohol; AVF: Arteriovenous malformation; PSA: Pseudoaneurysms; VM: Venous malformations; TS: Technical success; CS: Clinical success; NTE: Non target embolization

\section{Acknowledgements}

None.

\section{Authors' contributions}

AS was involved in the data collection and writing the manuscript. FR was involved in revising the manuscript. AC was involved in the data collection and revising the manuscript. RS was involved in revising the manuscript. AA was involved in revising the manuscript. DS was involved in revising the manuscript. AV was involved in revising the manuscript. SS was a major contributor in creation of project and revising manuscript. All authors read and approved the final manuscript.

\section{Authors' information}

Not applicable.

\section{Funding}

None.

\section{Availability of data and materials}

Not applicable.

\section{Ethics approval and consent to participate}

IRB approval was obtained.

\section{Consent for publication}

Institutional consent forms were used.

\section{Competing interests}

Not applicable.

Received: 23 November 2019 Accepted: 3 April 2020

Published online: 02 August 2020

\section{References}

Abularrage CJ et al (2012) Improved results using Onyx glue for the treatment of persistent type 2 endoleak after endovascular aneurysm repair. J Vasc Surg 56:630-636
Akin ED, Perkins E, Ross IB (2003) Surgical handling characteristics of an ethylene vinyl alcohol copolymer compared with n-butyl cyanoacrylate used for embolization of vessels in an arteriovenous malformation resection model in swine. J Neurosurg 98:366-370

Angle JF et al (2010) Quality improvement guidelines for percutaneous Transcatheter embolization. J Vasc Interv Radiol 21:1479-1486

Barral P, Saeed-Kilani M, Tradi F et al (2017) Transcatheter arterial embolization with ethylene vinyl alcohol polymer (Onyx) for the treatment of hemorrhage due to uterine arteriovenous malformations. Diagn Interventional imaging 98(5):415-421

Baum RA et al (2002) Treatment of type 2 endoleaks after endovascular repair of abdominal aortic aneurysms: comparison of transarterial and translumbar techniques. J Vasc Surg 35:23-29

Bommart S et al (2011) Transarterial ethylene vinyl alcohol copolymer visualization and penetration after embolization of life-threatening hemoptysis: technical and clinical outcomes. Cardiovasc Intervent Radiol 35: 668-675

Bryce Y, Lam CK, Ganguli S, Schiro BJ, Cooper K, Cline M, Oklu R, Vatakencherry G, Peña CS, Gandhi RT (2018 Sep) Step-by-step approach to Management of Type II Endoleaks. Tech Vasc Interv Radiol 21(3):188-195

Cantasdemir M et al (2012) The use of Onyx for embolization of peripheral vascular malformations in pediatric patients. Pediatr Surg Int 28:477-487

Carberry G, Dalvie P, Ozkan O (2013) 4:18 PM Abstract No. 222 - Onyx as a second-line embolic agent in peripheral applications. J Vasc Interv Radiol 24 : $\mathrm{S} 103$

Castaneda F et al (2002) Treatment of pelvic Arteriovenous malformations with ethylene vinyl alcohol copolymer (Onyx). J Vasc Interv Radiol 13:513-516

CIRSE (2017) Complications clasifications from Filippiadis. Cardiovasc Intervent Radiol 40:1141-1146

Coppi G, Saitta G, Coppi G (2014) Transealing: a novel and simple technique for embolization of type 2 endoleaks through direct sac access from the distal stent-graft landing zone. Eur J Vasc Endovasc Surg 47:394-401

Duffner F, Ritz R, Bornemann A, Freudenstein D, Wiendl H, Siekmann R (2002) Combined therapy of cerebral arteriovenous malformations: histological differences between a non-adhesive liquid embolic agent and n-butyl 2cyanoacrylate (NBCA). Clin Neuropathol 21:13-17

Eberhardt KM et al (2014) Treatment of type I Endoleaks using Transcatheter embolization with Onyx. J Endovasc Ther 21:162-171

Giles K, Fillinger M, De Martino R et al (2015) Results of transcaval embolization for sac expansion from endoleaks after endovascular aneurysm repair. J Vasc Surg 61:1129-1136

Guimaraes M, Wooster M (2011) Onyx (ethylene-vinyl alcohol copolymer) in peripheral applications. Semin Interv Radiol 28:350-356

Izaaryene J, Vidal V, Bartoli J-M, Gaubert J-Y (2016) Multiple bronchial artery aneurysms: successful treatment with ethylene-vinyl alcohol copolymer $\left(\right.$ Onyx $\left.{ }^{\circledast}\right)$. Diagn Interv Imaging 97:125-127

Jia JB, Green CS, Cohen AJ, Helmy M (2015) CT and radiographic appearance of extracranial Onyx ${ }^{\oplus}$ embolization. Clin Radiol 70:326-332

Khaja MS et al (2013) Treatment of type II Endoleak using Onyx with long-term imaging follow-up. Cardiovasc Intervent Radiol 37:613-622

Kilani M (2015) Saeed et al. ethylene vinyl alcohol copolymer (Onyx ${ }^{\circledR}$ ) in peripheral interventional radiology: indications, advantages and limitations. Diagn Interv Imaging 96:319-326

Kolber MK, Shukla PA, Kumar A, Silberzweig JE (2015) Ethylene vinyl alcohol copolymer (Onyx) embolization for acute hemorrhage: a systematic review of peripheral applications. J Vasc Interv Radiol 26:809-815

Lenhart $\mathrm{M}$ et al (2010) Superselective arterial embolisation with a liquid polyvinyl alcohol copolymer in patients with acute gastrointestinal haemorrhage. Eur Radiol 20:1994-1999

Loh Y, Duckwiler GR (2010) A prospective, multicenter, randomized trial of the Onyx liquid embolic system and N-butyl cyanoacrylate embolization of cerebral arteriovenous malformations. J Neurosurg 113:733-741

Marcelin C et al (2017) Safety and efficacy of embolization using Onyx ${ }^{\oplus}$ of persistent type II endoleaks after abdominal endovascular aneurysm repair. Diagn Interv Imaging. https://doi.org/10.1016/j.diii.2017.01.003

Massis K, Carson WG, Rozas A, Patel V, Zwiebel B (2012) Treatment of type II Endoleaks with ethylene-vinyl-alcohol copolymer (Onyx). Vasc Endovasc Surg 46:251-257

Müller-Wille R et al (2011) Endovascular treatment of acute arterial hemorrhage in trauma patients using ethylene vinyl alcohol copolymer (Onyx). Cardiovasc Intervent Radiol 35:65-75 
Murayama Y, Viñuela F, Ulhoa A, Akiba Y, Duckwiler GR, Gobin YP et al (1998) Nonadhesive liquid embolic agent for cerebral arteriovenous malformations: preliminary histopathological studies in swine rete mirabile. Neurosurgery 43 1164-1175

Murugesan C et al (2008) Severe pulmonary oedema following therapeutic embolization with Onyx for cerebral arteriovenous malformation. Neuroradiology 50(4p):439-442

Numan F et al (2004) Embolization of peripheral vascular malformations with ethylene vinyl alcohol copolymer (Onyx). J Vasc Interv Radiol 15:939-946

Pamuk AG, Saatci I, Cekirge HS, Aypar U (2005) A contribution to the controversy over dimethyl sulfoxide toxicity: anesthesia monitoring results in patients treated with Onyx embolization for intracranial aneurysms. Neuroradiology 47:380-386

Regine $R$ et al (2015) Embolization of traumatic and non-traumatic peripheral vascular lesions with Onyx. Interv Med Appl Sci 7:22-29

Salaskar AL, Laredo J, Marshall E, Venbrux AC (2020) Percutaneous embolization using a combination of liquid embolic agents for the treatment of a large disfiguring venous malformation. J Vasc Surg Cases Innov Tech 6(2):168-171.

Stavropoulos SW, Park J, Fairman R, Carpenter J (2009) Type 2 endoleak embolization comparison: translumbar embolization versus modified transarterial embolization. J Vasc Interv Radiol 20:1299-1302

Urbano J, Manuel Cabrera J, Franco A, Alonso-Burgos A (2014) Selective arterial embolization with ethylene-vinyl alcohol copolymer for control of massive lower gastrointestinal bleeding: feasibility and initial experience. J Vasc Interv Radiol 25:839-846

Vanninen RL, Manninen I (2007) Onyx, a new liquid embolic material for peripheral interventions: preliminary experience in aneurysm, Pseudoaneurysm, and pulmonary Arteriovenous malformation embolization. Cardiovasc Intervent Radiol 30:196-200

Velat GJ et al (2008) Comparison of N-butyl cyanoacrylate and onyx for the embolization of intracranial arteriovenous malformations: analysis of fluoroscopy and procedure times. Neurosurgery 63:ONS73-ONS78; discussion ONS78-80

Wildgruber M, Müller-Wille R, Busch V, Wohlgemuth WA, Heiss P (2016) Severe adverse reaction during DMSO injection for Onyx embolization of a thoracic type II Endoleak. Cardiovasc Intervent Radiol 39:144-145

Wohlgemuth WA et al (2015) The retrograde Transvenous push-through method: a novel treatment of peripheral Arteriovenous malformations with dominant venous outflow. Cardiovasc Intervent Radiol 38:623-631

Yang R, Tan K, Beercroft J et al (2016) Direct sac puncture versus transarterial embolization of type II endoleaks: An evaluation and comparison of outcomes. Vascular undefined:227-233

Zeleňák K, Sopilko I, Švihra J, Kliment J (2009) Successful embolization of a renal artery Pseudoaneurysm with Arteriovenous fistula and extravasations using Onyx after partial nephrectomy for renal cell carcinoma. Cardiovasc Intervent Radiol 32:163-165

\section{Publisher's Note}

Springer Nature remains neutral with regard to jurisdictional claims in published maps and institutional affiliations.

\section{Submit your manuscript to a SpringerOpen ${ }^{\circ}$ journal and benefit from:}

- Convenient online submission

- Rigorous peer review

- Open access: articles freely available online

- High visibility within the field

- Retaining the copyright to your article

Submit your next manuscript at $\boldsymbol{\nabla}$ springeropen.com 